\title{
Cerebral oxygenation and brain activity after perinatal asphyxia: does hypothermia change their prognostic value?
}

\author{
Petra M.A. Lemmers' ${ }^{1}$, Renee J. Zwanenburg' ${ }^{1}$, Manon J.N.L. Benders' ${ }^{1}$ Linda S. de Vries' ${ }^{1}$, Floris Groenendaal' ${ }^{1}$ Frank van Bel' \\ and Mona C. Toet ${ }^{1}$
}

BACKGROUND: Hypothermia is an established therapy in term neonates to reduce death and disability after perinatal asphyxia. Near-infrared spectroscopy-monitored regional cerebral oxygen saturation $\left(\mathrm{rSCO}_{2}\right)$ and amplitude-integrated electroencephalogram ( $\mathrm{aEEG}$ )-monitored background pattern have been shown to be early predictors of long-term neurodevelopmental outcome. The aim of this study was to investigate the prognostic value of $\mathrm{rScO}_{2}$ and $\mathrm{aEEG}$ for neurodevelopmental outcome in neonates with hypoxic-ischemic encephalopathy (HIE) treated with hypothermia.

METHODS: In neonates with HIE who were subjected to hypothermia, the aEEG background pattern and $\mathrm{rScO}_{2}$ were studied prospectively from admission up to $84 \mathrm{~h}$ in relation to early magnetic resonance imaging and neurodevelopmental outcome at 18 mo of age.

RESULTS: Of 39 infants, 12 neonates died because of neurological deterioration. One had an adverse outcome and 26 had a favorable outcome. The $\mathrm{rSCO}_{2}$ was higher in neonates with adverse outcome, although aEEG scores were lower. Positive predictive values at 12,24 , and $36 \mathrm{~h}$ of age for adverse outcome ranged from 50 to $67 \%$ for $\mathrm{rScO}_{2}$ and aEEG; negative predictive values ranged from 73 to $96 \%$ for $\mathrm{rScO}_{2}$ and 90 to $100 \%$ for aEEG. Combining $\mathrm{rSCO}_{2}$ and aEEG increased positive predictive values (70-91\%) and negative predictive values (90-100\%).

CONCLUSION: During hypothermia, $\mathrm{rScO}_{2}$ and aEEG measurements are early predictors of long-term outcome after HIE. Combining both parameters further improves early prediction.

$\mathrm{H}$ ypoxic-ischemic encephalopathy (HIE) due to perinatal asphyxia is still an important cause of adverse neurodevelopmental outcome and death with an incidence varying between 1 and 6 per 1,000 live births $(1,2)$.

A substantial part of perinatal asphyxia-induced brain damage is due to reoxygenation and reperfusion during the first $24-72 \mathrm{~h}$ of life $(3,4)$. This provides us with a "therapeutic window" in which reduction of brain injury can be achieved. Studies in hypoxic-ischemic neonatal animals have shown the reduction of brain damage using (combinations of) pharmacologic neuroprotective agents when started as soon as possible after birth and within a 6-h therapeutic window $(5,6)$. In the human neonate, however, mild hypothermia initiated within $6 \mathrm{~h}$ after birth is the only established therapy for reducing postasphyxial reperfusion injury to the newborn brain (7-10).

Amplitude-integrated electroencephalogram (aEEG)-monitored background pattern and near-infrared spectroscopy (NIRS)-monitored regional cerebral oxygen saturation $\left(\mathrm{rScO}_{2}\right)$ are important early predictors for long-term neurodevelopmental outcome after perinatal asphyxia, with high predictive values as early as 3-24h after birth during normothermia (1114). There are limited and conflicting data showing that this is also the case during hypothermia (15-17).

In the present prospective study, our aim is, therefore, to reevaluate the early predictive value of NIRS-monitored $\mathrm{rScO}_{2}$, cerebral fractional tissue oxygen extraction (cFTOE) and aEEG background pattern for neurodevelopmental outcome during and after hypothermia in term neonates with HIE.

\section{RESULTS}

\section{Important Patient Characteristics}

Forty-eight neonates fulfilled criteria for inclusion. However, three neonates were excluded because of congenital abnormalities (Down syndrome, pulmonary dysplasia, and diaphragmatic hernia), five were excluded because of a lack of reliable NIRS and/or aEEG registrations, and one infant was lost for follow-up after 3 mo of age. The characteristics of these patients, however, did not differ from included patients (data not shown).

Thirty-nine patients were eventually included. Twenty-four infants had a favorable outcome at 18 mo with a normal neurodevelopmental quotient (range 86-117). In two infants in the group with a favorable outcome, a Griffiths test was not performed at 18 mo of age, but a Bayley Scales of Infant and Toddler Development third edition test was performed at 24 mo of age. Both infants had scores within the normal range (total motor composite scores of 107 and 103, and cognitive composite scores of 90 and 115, respectively). Thirteen infants had an adverse outcome; 12 of these infants died after neurological deterioration followed by redirection of care in the neonatal period, and one infant had global developmental delay with a developmental quotient (DQ) of 76. Postnatal age 
at admission was not different between infants with favorable outcome and infants with adverse outcome, and all had a core temperature of $33.5^{\circ} \mathrm{C}$ at $6 \mathrm{~h}$ of life. Table 1 provides the patient characteristics of favorable and adverse outcome groups. There were no significant differences between the groups, except for the Thompson score on admission and presence of lesions on magnetic resonance imaging (MRI). The MRI scores of infants with adverse outcome were significantly higher compared with the favorable outcome group (median (range) $6(3-10)$ vs. $2(0-7), P<0.001)$. MRI was not performed in seven infants of the adverse outcome group, as they were too unstable to be transported to the MRI unit and died before the fourth day after birth. These infants had extensive abnormalities on sequential cranial ultrasound examinations with inactive aEEG recordings and/or seizures that were unresponsive to several antiepileptic drugs (confirmed with (repeated) standard EEG examinations). In seven of the 12 infants who died, permission for postmortem investigation was obtained. All showed severe generalized brain damage (extensive hypoxicischemic brain injury) with histological signs of cell death and cytotoxic edema.

Table 1. Important patient characteristics

\begin{tabular}{|c|c|c|c|}
\hline & $\begin{array}{l}\text { Favorable } \\
\text { outcome }\end{array}$ & $\begin{array}{l}\text { Adverse } \\
\text { outcome }\end{array}$ & \\
\hline Characteristic & $n=26$ & $n=13$ & $P$ value \\
\hline $\begin{array}{l}\text { Gestational age, weeks } \\
\text { (mean } \pm \text { SD) }\end{array}$ & $40.32 \pm 1.50$ & $40.21 \pm 1.26$ & ns \\
\hline $\begin{array}{l}\text { Birth weight, grams } \\
\text { (mean } \pm S D \text { ) }\end{array}$ & $3,744 \pm 644$ & $3,831 \pm 603$ & ns \\
\hline Gender & & & ns \\
\hline Male $(n(\%))$ & $16(62)$ & $8(62)$ & \\
\hline Female $(n(\%))$ & $10(38)$ & $5(38)$ & \\
\hline 5 min Apgar (median (range)) & $3(1-6)$ & $3(0-7)$ & ns \\
\hline First pH (mean \pm SD) & $6.97 \pm 0.2$ & $6.90 \pm 0.3$ & ns \\
\hline First base excess (mean \pm SD) & $-16.4 \pm 6.4$ & $-13.1 \pm 8.3$ & ns \\
\hline Lactate (mean $\pm \mathrm{SD})$ & $14.3 \pm 6.9$ & $12.1 \pm 8.5$ & ns \\
\hline Ventilation support ( $n(\%))$ & $23(88)$ & $13(100)$ & ns \\
\hline Inotropics (n (\%)) & $21(80)$ & $12(92)$ & ns \\
\hline Nitric oxide ventilation ( $(\%)$ ) & $10(38)$ & $3(23)$ & ns \\
\hline PPHN ( $n(\%))$ & $10(38)$ & $4(30)$ & ns \\
\hline Seizures (n (\%)) & $15(59)$ & $13(100)$ & ns \\
\hline $\begin{array}{l}\text { Thompson score } \\
\text { (median (range)) }\end{array}$ & $10(7-13)$ & $12(8-14)$ & 0.04 \\
\hline \multicolumn{4}{|l|}{ CUS } \\
\hline $\begin{array}{l}\text { Increased periventricular } \\
\text { echogenicity }(n(\%))\end{array}$ & $14(53)$ & $5(38)$ & ns \\
\hline Subcortical densities ( $n(\%))$ & $15(57)$ & $8(61)$ & ns \\
\hline Basal ganglia/thalamus ( $n(\%)$ ) & $12(46)$ & $9(69)$ & ns \\
\hline MRI & $n=26$ & $n=6$ & \\
\hline Total MR score (median (range)) & $2(0-7)$ & $6(3-10)$ & $<0.001$ \\
\hline
\end{tabular}

\section{NIRS and aEEG Patterns}

At admission, before starting total body cooling, $\mathrm{rScO}_{2}$ values were not different between the groups (mean \pm SD: $63 \pm 10$ vs. $68 \pm 14 \%$ in the adverse and favorable outcome group, respectively). $\mathrm{rScO}_{2}$ values for both outcome groups increased over postnatal age, but this increase was modest in the group with favorable outcome and normalized after reaching normal body temperature again at $84 \mathrm{~h}$ of age. In the group with an adverse outcome, $\mathrm{rScO}_{2}$ reached high values from $24 \mathrm{~h}$ of life onward (Figure 1a). $\mathrm{rScO}_{2}$ values were significantly higher in this group as compared with the favorable outcome group at $24,36,48$, and 84 h postnatally (mean \pm SD: $82 \pm 7$ vs. $72 \pm 9 \%$, $83 \pm 9$ vs. $75 \pm 8 \%, 83 \pm 10$ vs. $76 \pm 8 \%, 79 \pm 10$ vs. $72 \pm 9 \%, P<$ $0.001, P<0.01, P<0.05$, and $P<0.02$, respectively). The mean cFTOE value mirrored the patterns of $\mathrm{rScO}_{2}$ of both groups and became very low from $24 \mathrm{~h}$ of age onward in the adverse outcome group as compared with the favorable outcome group
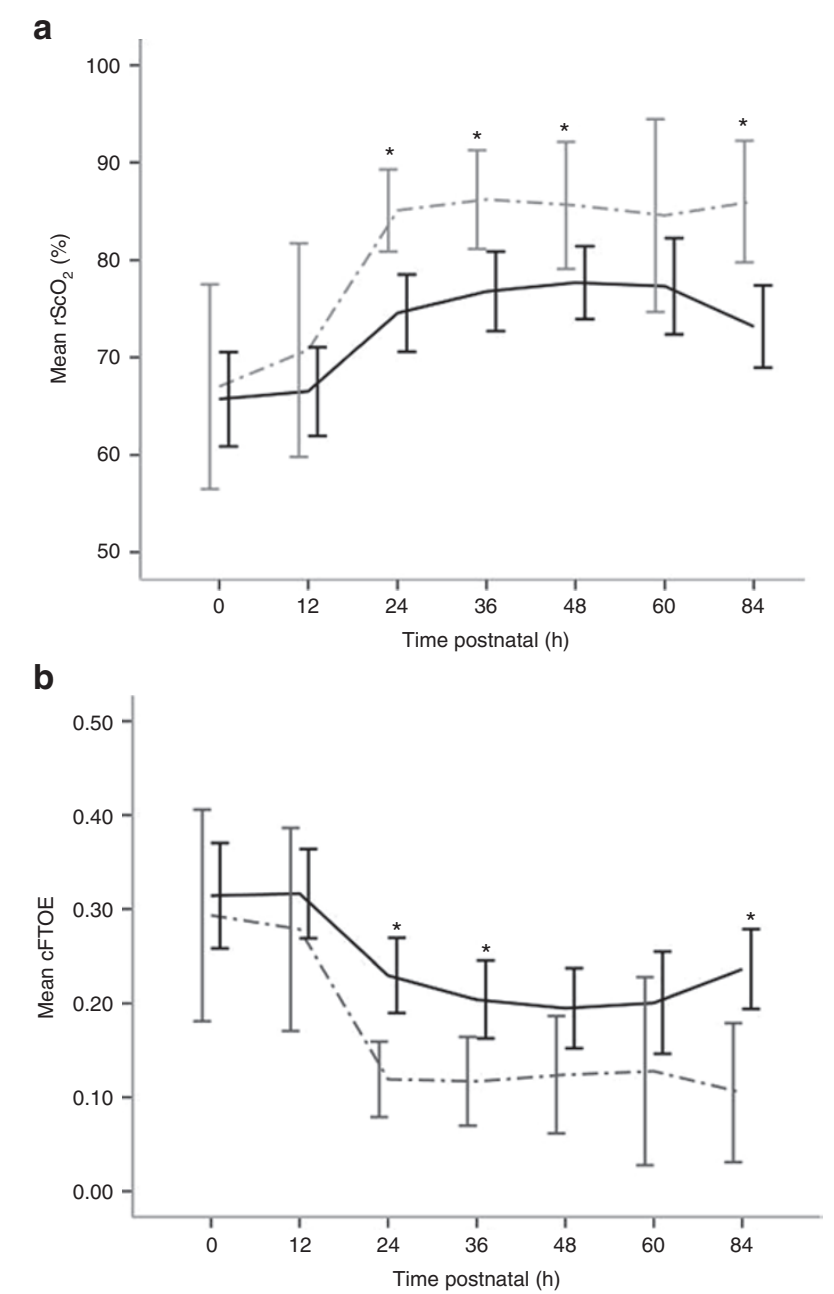

Figure 1. (a) Regional cerebral oxygen saturation $\left(\mathrm{rScO}_{2}\right)(\%)$ and (b) cerebral fractional tissue oxygen extraction (CFTOE) (mean and 95\% confidence interval) of neonates with hypoxic-ischemic encephalopathy (HIE) with favorable outcome (solid line) and adverse outcome (death or adverse neurodevelopmental outcome at $18 \mathrm{mo}$ of life (dashed line) during the first $84 \mathrm{~h}$ after birth $(* P<0.001$ (24h), $P<0.01$ (36h), $P<0.05$ (48h), $P<0.02$ (84h); and $P<0.001$ (24h), $P<0.02$ (36h), $P<0.02$ (84h), respectively)). 
(Figure 1b). Significant differences in cFTOE were found at 24, 36 , and $84 \mathrm{~h}$ postnatally (mean \pm SD: $0.14 \pm 0.07$ vs. $0.25 \pm 0.09$, $0.14 \pm 0.08$ vs. $0.21 \pm 0.09,0.24 \pm 0.1$ vs. $0.17 \pm 0.1, P<0.001, P$ $<0.02$, and $P<0.02$, respectively).

aEEG scores of both outcome groups increased during hypothermia. Scores were higher in the favorable outcome group as compared with those of the adverse outcome group at all points of time $(P<0.001$ to $P<0.02)$ (Figure 2$)$.

\section{Prediction of Outcome}

Receiver-operating curves (ROCs) were calculated for $\mathrm{rScO}_{2}$ and aEEG scores. However, in order to evaluate the predictive ability of $\mathrm{rScO}_{2}$ and aEEG score in one ROC graph, we first needed to reverse the aEEG score; therefore, direction toward adverse outcome is equalized for both parameters. This reversed score is indicated by aEEG-"rev", and background

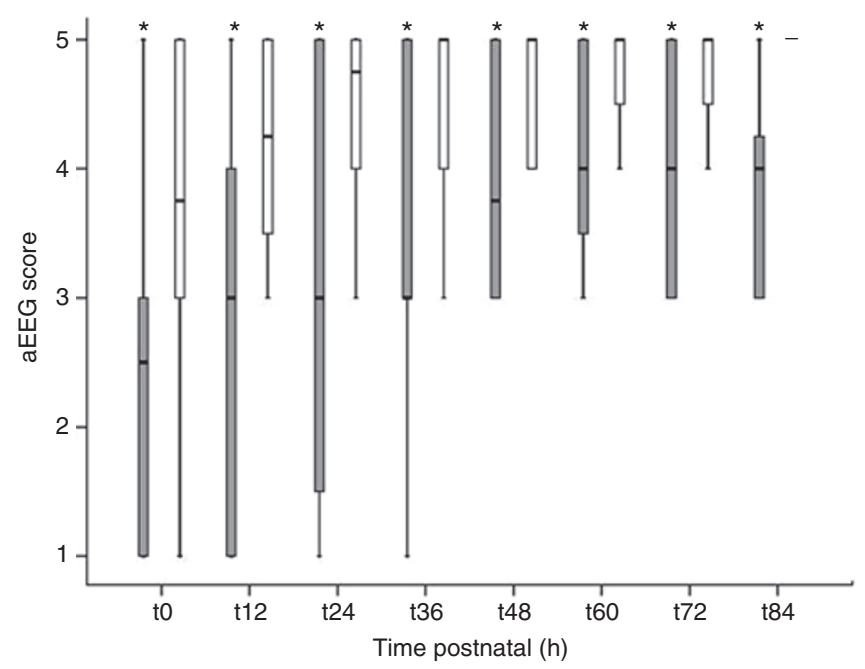

Figure 2. Amplitude-integrated electroencephalogram (aEEG) scores (median (range)) of neonates with hypoxic-ischemic encephalopathy (HIE) with favorable outcome (white bars) and adverse outcome (death or adverse neurodevelopmental outcome at 18 mo of life; gray bars) during the first $84 \mathrm{~h}$ after birth $\left({ }^{*} P<0.001(0=\right.$ admission $) ; P<0.0001$ (12h); $P<0.0001$ (24h); $P<0.01$ (36h); $P<0.02$ (48h); $P<0.02$ (60h); $P<0.01$ (72h); $P<0.01$ (84h)). patterns were defined as follows: continuous normal voltage, score 1; discontinuous normal voltage, score 2; burst suppression, score 3 ; continuous extremely low voltage, score 4; and flat trace (FT), score 5 .

To evaluate the additional predictive value of the combination of $\mathrm{rScO}_{2}$ and aEEG, we multiplied $\mathrm{rScO}_{2}$ with aEEGrev, indicated by the combined score. Figure 3 shows the ROCs of $\mathrm{rScO}_{2}$, aEEG-rev, and the combined score at $12 \mathrm{~h}$ (Figure 3a), $24 \mathrm{~h}$ (Figure 3b) and $36 \mathrm{~h}$ (Figure 3c) after birth. At all time points, aEEG-rev has a better area under the curve than $\mathrm{rScO}_{2}(0.92$ vs. $0.57 ; 0.88$ vs. 0.81 ; and 0.85 vs. 0.78 ), and both parameters combined (combined score) further increased the area under the curve as compared with aEEG-rev alone $(0.95,0.93$, and 0.86$)$.

Predictive values for $\mathrm{rScO}_{2}$, normal aEEG score and the combined score were calculated from $2 \times 2$ tables, and the results are shown in Table 2 . A cut-off value of $77 \%$ was used for abnormal $\mathrm{rScO}_{2}$ and 210 for an abnormal combined score. At all time points, positive predictive values of $\mathrm{rScO}_{2}$ and $\mathrm{aEEG}$ ranged from 50 to $67 \%$, whereas negative predictive values ranged from 73 to $96 \%$ for $\mathrm{rScO}_{2}$ and 90 to $100 \%$ for aEEG. Of note, the combined score did not increase negative predictive values, but it clearly increased positive predictive values at all time points, and the most striking result was the prediction of outcome as early as $12 \mathrm{~h}$ postnatally.

\section{Logistic Regression Analysis}

There was no correlation between $\mathrm{rScO}_{2}$ and aEEG score at 12,24 , and $36 \mathrm{~h}$ postnatally $(r=-0.03, P=0.88 ; r=-0.26$, $P=0.12 ; r=-0.21, P=0.25)$. Univariate logistic regression revealed significant results only at 24 and $36 \mathrm{~h}$ postnatal for both parameters $\left(\mathrm{rScO}_{2}: \beta-0.145, P=0.006\right.$ and $\beta-0.129, P$ $=0.018$, respectively; aEEG: $\beta 3.483, P=0.002$ and $\beta 2.197$, $P=0.017$, respectively). When the significant variables of univariate analysis were used for a regression model, the prediction of adverse outcome was correctly predicted in $94.7 \%$ (adverse 12/13, favorable 24/25) and 83.9\% (adverse 6/8, favorable 20/23) of the cases at 24 and 36 h after birth, respectively. For the combined score, univariate logistic regression revealed
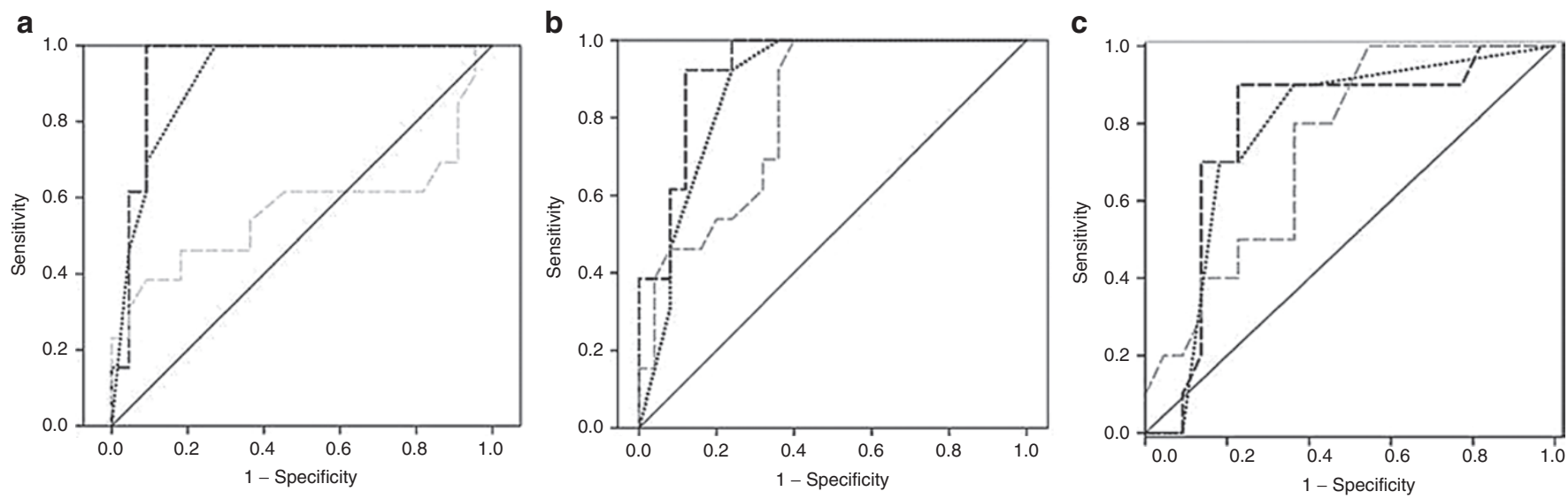

Figure 3. Receiver-operating curves of regional cerebral oxygen saturation $\left(\mathrm{rScO}_{2}\right)$ score (gray dashed line), reversed amplitude-integrated electroencephalogram (aEEG-"rev") score (black small dashed line), and the combined rScO2-aEEG-"rev" score (black dashed line) at (a) 12, (b) 24, and (c) 36h after birth. 
Table 2. Predictive values of $\mathrm{rScO}_{2}$, $\mathrm{aEEG}$ score, and the combined score

\begin{tabular}{lccc}
\hline 12-18 h & $\mathrm{rScO}_{2}$ & aEEG & Combined \\
\hline Sensitivity (\%) & 46 & 100 & 100 \\
Specificity (\%) & 86 & 69 & 87 \\
PPV (\%) & 67 & 62 & 91 \\
NPV (\%) & 73 & 100 & 100 \\
24-30 h & $\mathrm{rScO}_{2}$ & $\mathrm{aEEG}$ & Combined \\
Sensitivity (\%) & 92 & 92 & 92 \\
Specificity (\%) & 64 & 76 & 88 \\
PPV (\%) & 57 & 66 & 80 \\
NPV (\%) & 94 & 95 & 95 \\
36-42 h & $\mathrm{rScO}_{2}$ & $\mathrm{aEEG}$ & Combined \\
Sensitivity (\%) & 90 & 77 & 77 \\
Specificity (\%) & 65 & 73 & 86 \\
PPV (\%) & 53 & 50 & 70 \\
NPV (\%) & 96 & 90 & 90 \\
\hline
\end{tabular}

aEEG, amplitude-integrated electroencephalogram; NPV, negative predictive value; PPV, positive predictive value; $\mathrm{rSCO}_{2}$, regional cerebral oxygen saturation.

significant results at 12,24 , and 36 h postnatal $(\beta-0.037, P=$ $0.007, \beta-0.017, P=0.001$ and $\beta-0.016, P=0.016$, respectively) and outcome was correctly predicted in $91.4,78.9$, and $78.1 \%$ of the cases, respectively.

\section{DISCUSSION}

The present study shows that during mild hypothermia, $\mathrm{rScO}_{2}$ values are higher and aEEG-determined background pattern scores are lower in neonates with HIE with a subsequent adverse neurodevelopmental outcome. This is in line with the results obtained in newborn infants with HIE not treated with hypothermia, as reported by our group in 2006 (12). The difference is that during hypothermia, $\mathrm{rScO}_{2}$ values of neonates with a favorable outcome also tend to increase between 12 and $24 \mathrm{~h}$, but remain within the normal reference range of 55-85\% of healthy controls in the literature (18). We postulate that this may be due to the effect of mild hypothermia on cerebral metabolism, resulting in lower utilization of oxygen.

Further analysis revealed that $\mathrm{rScO}_{2}$ and aEEG background activity in particular are strong early predictors of favorable outcome in neonates after severe perinatal asphyxia subjected to hypothermia but are less reliable for predicting adverse outcome. Although previous predictive values for NIRS are scarce, aEEG has been investigated several times in infants with HIE treated normothermic with as well as hypothermia $(11,12,16,19)$. As compared with normothermia, the predictive value of aEEG appears to be postponed in neonates subjected to hypothermia. Our lower predictive values of aEEG from $24 \mathrm{~h}$ onward for adverse outcome during mild hypothermia are similar to several previous studies; however, they contrast with the positive predictive values reported in the study by Thoresen et al. (16). Although the inclusion criteria, perinatal characteristics, and outcome characteristics appear to be similar, the hypothermia group in the study by Thoresen et al. appears to consist of neonates with more severe symptoms of brain damage at that point in time than the infants in our study $(7,9,10)$. Another reason for the difference could be the death of four patients with a flat aEEG between 24 and $36 \mathrm{~h}$ in our adverse group. However, the favorable outcome group also contained patients with depressed aEEG at $36 \mathrm{~h}$ owing to high levels of midazolam. This might be an explanation for the wide range of aEEG background pattern score at that point in time.

Our results confirm the results of a comparable study by Ancora et al. (17). This study included 12 neonates and reported short-term neurodevelopmental outcome at $1 \mathrm{y}$ of age. Moreover, the infants included were selected for mild hypothermia only on the basis of moderate-to-severe HIE using the Sarnat score.

The present study is, as far as we know, to evaluate the additional value of a combined score of NIRS and aEEG in prediction of neurodevelopmental outcome in these group of infants. We were able to show that the individual positive predictive value of NIRS and aEEG can be significantly improved by combining $\mathrm{rScO}_{2}$ and aEEG (67 and $62 \%$ vs. $91 \%$, respectively), enabling us to reliably predict outcome as early as $12 \mathrm{~h}$ postnatally.

Our study also has limitations. The adverse outcome group consisted of 12 neonates who died following redirection of care in view of a combination of neuroimaging and electrophysiological data, and only one child of the adverse neurodevelopmental outcome group survived and had a long-term follow-up. The severity of brain injury was confirmed using postmortem examination in seven of those who died; cranial ultrasound or MRI showed severe basal ganglia and thalamic lesions, which are known to be associated with major disability (20). Although it is sometimes suggested that Dutch hospitals have a more liberal policy with regard to redirection of care, our mortality rate in this cohort of patients is not different from the rates reported in other studies $(7,9,10)$.

\section{Conclusion}

In conclusion, during mild hypothermia after moderateto-severe encephalopathy due to perinatal asphyxia, NIRSmonitored $\mathrm{rScO}_{2}$ and aEEG background pattern scores could be used as early predictors for neurodevelopmental outcome at 18 mo of age after perinatal asphyxia. Combining both parameters further increased the accuracy of early prediction of long-term neurodevelopmental outcome. Further research, however, should be performed to confirm our results.

\section{METHODS}

From January 2008 to December 2009, term infants with moderateto-severe perinatal asphyxia treated with mild hypothermia were potential candidates for this study.

Infants were included according to our whole-body cooling protocol, which consists of the following criteria: (i) gestational age $\geq 36 \mathrm{wk}$; (ii) evidence of perinatal asphyxia by one of the following: Apgar score 5 or less after $5 \mathrm{~min}$, resuscitation or ventilation at least $10 \mathrm{~min}$, cord or first $\mathrm{pH}$ (within $1 \mathrm{~h}$ of age) $<7.00$ with a base deficit $>16 \mathrm{mmol} / \mathrm{l}$ or serum lactate $>10 \mathrm{mmol} / \mathrm{l}$; (iii) signs of encephalopathy as demonstrated by a Thompson score $\geq 7$ (21) and/or abnormal brain activity by aEEG (see also below); and (iv) initiation of hypothermia possible 
within $6 \mathrm{~h}$ after birth. Infants with congenital abnormalities, perinatal infections of the central nervous system, chromosomal disorders, or longstanding hypoglycemia were excluded from the study.

As soon as possible after admission, aEEG and NIRS monitoring was started as part of standard clinical care. The aEEG and NIRS recordings started upon admission and well before the start of controlled hypothermia using CritiCool (Charter Kontron, Milton Keynes, UK), and were continued for at least $4 \mathrm{~d}$. Hypothermia was initiated within $6 \mathrm{~h}$ after birth, lasted for $72 \mathrm{~h}$, and aimed for a rectally measured body temperature of $33.5^{\circ} \mathrm{C}$. Seventy-two hours after starting hypothermia, subsequent rewarming at $0.5^{\circ} \mathrm{C}$ per hour was performed. Body temperature $\left({ }^{\circ} \mathrm{C}\right)$, heart rate, arterial blood pressure, and arterial oxygen saturation $\left(\mathrm{SaO}_{2}\right)$ were monitored simultaneously with $\mathrm{rScO}_{2}$ and aEEG, and were all stored on a personal computer for off-line analysis (software: Poly 5; Inspektor Research Systems, Amsterdam, The Netherlands), with a sampling frequency of $10 \mathrm{~Hz}$. The Thompson score was used to assess the degree of HIE (22). Cranial ultrasound, MRI, and follow-up were all part of normal clinical care after severe perinatal asphyxia: cranial ultrasound was performed at admission and repeated at days $1,2,3,5$, and 7, MRI at 4-6 d after birth and the Griffiths Mental Developmental scales at 18 mo. The study was approved by the Medical Ethical Committee of the University Medical Center Utrecht, and informed parental consent was obtained in all cases.

\section{Monitoring Cerebral Oxygenation and Extraction Using NIRS}

Changes in $\mathrm{rScO}_{2}$ and $\mathrm{cFTOE}$ were monitored using a two-wavelength (730 and $810 \mathrm{~nm}$ ) near-infrared spectrometer (INVOS 41005100; Somanetics, Troy, MI). A transducer (small adult SomaSensor SAFB-SM) containing a light-emitting diode and two distant sensors (30 and $40 \mathrm{~mm}$ ) was placed on the frontoparietal side of the infant's head and attached with an elastic bandage to prevent displacement and ambient light $(18,23)$. $\mathrm{rScO}_{2}$ was calculated from differential signals obtained from two sensors, expressed as the venous-weighted percentage of oxygenated hemoglobin (oxygenated hemoglobin/ total hemoglobin (with total hemoglobin $=$ oxygenated hemoglobin + deoxygenated hemoglobin)) (23). Because this parameter provides absolute values, $\mathrm{rScO}_{2}$ is less subject to movement artifacts, and important comparisons over time are possible $(24,25)$. To investigate the balance between oxygen delivery and oxygen consumption, cFTOE can be formulated as a ratio: $\left(\mathrm{SaO}_{2}-\mathrm{rScO}_{2}\right) / \mathrm{SaO}_{2}$. An increase in cFTOE reflects an increase of the oxygen extraction by brain tissue, and a decrease suggests less utilization of oxygen by brain tissue in comparison with the oxygen supply $(26,27)$.

\section{Monitoring Background Patterns of the Brain Using aEEG}

Electrical brain activity was monitored using an amplitude-integrated EEG monitor (Olympic 6000 or Brainz BRM; Natus, Seattle, WA), which records a single or two channel EEG from 2 to 4 parietal electrodes. The filtered signal is rectified and smoothed, and the amplitude is integrated. Different aEEG patterns are provided by means of pattern recognition and scoring: FT (very low voltage, mainly inactive (isoelectric) tracing with activity below $5 \mu \mathrm{V}$ : score 1 ); continuous extremely low voltage (continuous background pattern of very low voltage (approximately or below $5 \mu \mathrm{V}$ ): score 2); burst suppression (discontinuous background pattern: score 3; periods of very low voltage (inactivity) intermixed with burst of higher amplitude; score 3); discontinuous normal voltage (discontinuous trace, whereby the voltage is predominantly $>5 \mathrm{mV}$ : score 4 ); and continuous normal voltage (continuous activity with voltage $10-25(-50) \mu \mathrm{V}$ : score 5$)(19,28)$.

\section{MRI}

The severity of brain injury was assessed by using conventional T1and T2-weighted spin echo sequences, with diffusion-weighted imaging and apparent diffusion coefficient maps when available. Injury was scored for the basal ganglia and thalami in combination with cortical involvement, the watershed areas, and the posterior limb of the internal capsule by using systems described previously as being predictive for neurodevelopmental outcomes after HIE (29,30). A total score was calculated. The number of the score depends on the severity of abnormalities in different regions as detected by MRI (from $0=$ no abnormalities to 11 = severe abnormalities). Examiners of MRI were blinded for aEEG and $\mathrm{rScO}_{2}$ results.

\section{Neurodevelopmental Outcome}

The Griffiths Mental Developmental Scales at the age of 18 mo (31) were used to assess motor and cognitive performance as a routinely performed outpatient clinic follow-up tool. This scale comprises five subscales, including locomotor, personal, and social, hearing and speech, eye hand coordination, performance, and practical reasoning, from which an overall DQ is derived. From these subscales, a DQ can be calculated. A DQ $<85(100-1 \mathrm{SD})$ is considered as a delayed neurological development, whereas a DQ of 85 or more indicates favorable neurodevelopmental outcome. Adverse neurodevelopmental outcome was defined as neonatal mortality or a DQ $<85$. Neurological development assessment was performed by a trained investigator who was blinded for aEEG and $\mathrm{rScO}_{2}$ results.

\section{Study Design}

Patients were prospectively included and mean values of $\mathrm{SaO}_{2}, \mathrm{rScO}_{\text {, }}$, FTOE, and mean arterial blood pressure were calculated over a $1-h^{\prime}$ period at admission and at $12,24,36,48,60$, and $84 \mathrm{~h}$ of age. In the same time intervals, aEEG background patterns were analyzed over a 6-h period (at admission, 12-18 h, 24-30 h, 36-42 h, 48-54h, 60-68 h, and $84-90 \mathrm{~h}$ of age) using a scoring system representing the different background patterns as discussed above: continuous normal voltage, score 5; discontinuous normal voltage, score 4; burst suppression, score 3 ; continuous extremely low voltage, score 2 ; and FT, score 1 .

\section{Statistical Analysis}

Patient characteristics were summarized as means \pm SD or as median and ranges where appropriate. Differences in patient characteristics between neonates with adverse and favorable outcomes were compared using Student's $t$-test, $\chi^{2}$ test or Fisher's exact test where appropriate. Furthermore, Student's $t$-test or Mann-Whitney $U$-test was used to assess changes in $\mathrm{rScO}_{2}, \mathrm{cFTOE}$, and aEEG score between the adverse and favorable groups at the various points of time.

ROCs were used to compare the predictive ability of $\mathrm{rScO}_{2}$, aEEG score, and the additional value of both parameters combined. As our aim is to find early predictors of adverse outcome during mild hypothermia, ROCs were calculated only for early time points within this period: $t=12,24$, and $36 \mathrm{~h}$ postnatally. Furthermore, $2 \times 2$ tables were constructed to calculate sensitivity, specificity, positive predictive value, and negative predictive value of the three variables $\mathrm{rScO}_{2}$, $\mathrm{aEEG}$, and $\mathrm{rScO}_{2}$ and aEEG combined. A normal aEEG score was defined as a score of 4 or 5 (discontinuous normal voltage or continuous normal voltage) and abnormal aEEG scores as 3 or lower (burst suppression, continuous extremely low voltage and FT), equally to Thoresen et al. (16). For $\mathrm{rScO}_{2}$, aEEG score, and the combination of $\mathrm{rScO}_{2}$ and aEEG score, we used the ROCs to find the optimal "cutoff" points.

In addition, multiple logistic regression analysis was used to evaluate the predictive value of a logistic regression model for adverse outcome based on $\mathrm{rScO}_{2}$ and the presence of an abnormal aEEG score at $t=12-16,24-30$, and $36-40 \mathrm{~h}$ postnatally. Correlation analysis was then performed to control for multicolinearity between $\mathrm{rScO}_{2}$ and the presence of an abnormal aEEG score. For statistical analysis, SPSS for Windows, version 15, was used. Significance was assumed for $P<0.05$.

Disclosure: The authors have no financial relationships relevant to this article to disclose.

\section{REFERENCES}

1. Dilenge ME, Majnemer A, Shevell MI. Long-term developmental outcome of asphyxiated term neonates. J Child Neurol 2001;16:781-92.

2. Black RE, Cousens S, Johnson HL, et al.; Child Health Epidemiology Reference Group of WHO and UNICEF. Global, regional, and national causes of child mortality in 2008: a systematic analysis. Lancet 2010;375:1969-87. 
3. Lorek A, Takei Y, Cady EB, et al. Delayed ("secondary”) cerebral energy failure after acute hypoxia-ischemia in the newborn piglet: continuous 48-hour studies by phosphorus magnetic resonance spectroscopy. Pediatr Res 1994;36:699-706.

4. Volpe JJ. Perinatal brain injury: from pathogenesis to neuroprotection. Ment Retard Dev Disabil Res Rev 2001;7:56-64.

5. van Bel F, Groenendaal F. Long-term pharmacologic neuroprotection after birth asphyxia: where do we stand? Neonatology 2008;94:203-10.

6. Ferriero DM. Neonatal brain injury. N Engl J Med 2004;351:1985-95.

7. Gluckman PD, Wyatt JS, Azzopardi D, et al. Selective head cooling with mild systemic hypothermia after neonatal encephalopathy: multicentre randomised trial. Lancet 2005;365:663-70.

8. Shankaran S, Laptook AR, Ehrenkranz RA, et al.; National Institute of Child Health and Human Development Neonatal Research Network. Whole-body hypothermia for neonates with hypoxic-ischemic encephalopathy. N Engl J Med 2005;353:1574-84.

9. Azzopardi DV, Strohm B, Edwards AD, et al.; TOBY Study Group. Moderate hypothermia to treat perinatal asphyxial encephalopathy. N Engl J Med 2009;361:1349-58.

10. Simbruner G, Mittal RA, Rohlmann F, Muche R; neo.nEURO.network Trial Participants. Systemic hypothermia after neonatal encephalopathy: outcomes of neo.nEURO.network RCT. Pediatrics 2010;126:e771-8.

11. Toet MC, Hellström-Westas L, Groenendaal F, Eken P, de Vries LS. Amplitude integrated EEG 3 and 6 hours after birth in full term neonates with hypoxic-ischaemic encephalopathy. Arch Dis Child Fetal Neonatal Ed 1999;81:F19-23.

12. Toet MC, Lemmers PM, van Schelven LJ, van Bel F. Cerebral oxygenation and electrical activity after birth asphyxia: their relation to outcome. Pediatrics 2006;117:333-9.

13. al Naqeeb N, Edwards AD, Cowan FM, Azzopardi D. Assessment of neonatal encephalopathy by amplitude-integrated electroencephalography. Pediatrics 1999;103(6 Pt 1):1263-71.

14. ter Horst HJ, Sommer C, Bergman KA, Fock JM, van Weerden TW, Bos AF. Prognostic significance of amplitude-integrated EEG during the first 72 hours after birth in severely asphyxiated neonates. Pediatr Res 2004;55:1026-33.

15. Hallberg B, Grossmann K, Bartocci M, Blennow M. The prognostic value of early aEEG in asphyxiated infants undergoing systemic hypothermia treatment. Acta Paediatr 2010;99:531-6.

16. Thoresen M, Hellström-Westas L, Liu X, de Vries LS. Effect of hypothermia on amplitude-integrated electroencephalogram in infants with asphyxia. Pediatrics 2010;126:e131-9.

17. Ancora G, Maranella E, Grandi S, et al. Early predictors of short term neurodevelopmental outcome in asphyxiated cooled infants. A combined brain amplitude integrated electroencephalography and near infrared spectroscopy study. Brain Dev 2013;35:26-31.

18. van Bel F, Lemmers P, Naulaers G. Monitoring neonatal regional cerebral oxygen saturation in clinical practice: value and pitfalls. Neonatology 2008;94:237-44.

19. Hellström-Westas L, Rosén I, Svenningsen NW. Predictive value of early continuous amplitude integrated EEG recordings on outcome after severe birth asphyxia in full term infants. Arch Dis Child Fetal Neonatal Ed 1995;72:F34-8.

20. Martinez-Biarge M, Diez-Sebastian J, Kapellou O, et al. Predicting motor outcome and death in term hypoxic-ischemic encephalopathy. Neurology 2011;76:2055-61.

21. Thompson CM, Puterman AS, Linley LL, et al. The value of a scoring system for hypoxic ischaemic encephalopathy in predicting neurodevelopmental outcome. Acta Paediatr 1997;86:757-61.

22. Sarnat HB, Sarnat MS. Neonatal encephalopathy following fetal distress. A clinical and electroencephalographic study. Arch Neurol 1976;33:696-705.

23. Greisen G. Is near-infrared spectroscopy living up to its promises? Semin Fetal Neonatal Med 2006;11:498-502.

24. Menke J, Voss U, Möller G, Jorch G. Reproducibility of cerebral near infrared spectroscopy in neonates. Biol Neonate 2003;83:6-11.

25. Dullenkopf A, Kolarova A, Schulz G, Frey B, Baenziger O, Weiss M. Reproducibility of cerebral oxygenation measurement in neonates and infants in the clinical setting using the NIRO 300 oximeter. Pediatr Crit Care Med 2005;6:344-7.

26. Wardle SP, Garr R, Yoxall CW, Weindling AM. A pilot randomised controlled trial of peripheral fractional oxygen extraction to guide blood transfusions in preterm infants. Arch Dis Child Fetal Neonatal Ed 2002;86:F227.

27. Naulaers G, Meyns B, Miserez M, et al. Use of tissue oxygenation index and fractional tissue oxygen extraction as non-invasive parameters for cerebral oxygenation. A validation study in piglets. Neonatology 2007;92:120-6.

28. Toet MC, van der Meij W, de Vries LS, Uiterwaal CS, van Huffelen KC. Comparison between simultaneously recorded amplitude integrated electroencephalogram (cerebral function monitor) and standard electroencephalogram in neonates. Pediatrics 2002;109:772-9.

29. Mercuri E, Ricci D, Cowan FM, et al. Head growth in infants with hypoxicischemic encephalopathy: correlation with neonatal magnetic resonance imaging. Pediatrics 2000;106(2 Pt 1):235-43.

30. Barkovich AJ, Hajnal BL, Vigneron D, et al. Prediction of neuromotor outcome in perinatal asphyxia: evaluation of MR scoring systems. AJNR Am J Neuroradiol 1998;19:143-9.

31. Griffiths R. A study in mental measurement. Association for research in infant an child development. 1976. 